\title{
Installation Aerodynamics of Civil Aero-Engine Exhaust Systems
}

\author{
John J. Otter ${ }^{\mathrm{a}, *}$, Tomasz Stańkowski ${ }^{\mathrm{a}}$, Matthew Robinson ${ }^{\mathrm{a}}$, David G \\ MacManus $^{\text {a }}$ \\ ${ }^{a}$ Propulsion Engineering Centre, School of Aerospace, Transport and Manufacturing, \\ Cranfield University, Bedfordshire, MK43 OAL
}

\begin{abstract}
Without careful consideration of aerodynamic installation effects on exhaust system performance the projected benefits of high bypass ratio engines may not be achievable. This work presents a computational study of propulsion system integration in order to quantify the effect that aircraft installation has on the aerodynamic performance of separate-jet aero-engine exhaust systems. Within this study the sensitivity of exhaust nozzle performance metrics to aircraft incidence and under wing position were investigated for two engines of different specific thrust. Upon installation, thrust generation was found to be beneficial or detrimental relative to an isolated engine depending on the position of the engine relative to the wing leading edge. The dominant installation effect was observed on the exhaust afterbodies and, over the range of engine positions investigated at cruise conditions, the installed modified velocity coefficient was shown to vary up to $1 \%$ relative to an isolated engine. Furthermore, due to variations in the core nozzle mass flow rate by
\end{abstract}

\footnotetext{
*Corresponding author.

E-mail address: jjotter26@gmail.com
}

Preprint submitted to Aerospace Science and Technology (AESCTE) February 14, 2019 
up to $10 \%$ relative to an isolated engine, it is concluded that aerodynamic installation effects need to be taken into consideration when sizing the core nozzle in order to ensure engine operability.

Keywords: Engine-airframe integration, Exhaust nozzle, Aero-engine, Discharge coefficient, Velocity coefficient;Computational fluid dynamics; Propulsion system integration.

\section{Nomenclature}

\section{Roman Symbols}

$\alpha \quad$ Angle of Attack

degrees

$\dot{m} \quad$ Mass flow rate

$k g s^{-1}$

$c \quad$ Wing Chord

$\mathrm{m}$

$C_{d}^{\text {Bypass }}, C_{d}^{\text {Core }}$ Bypass and Core Discharge Coefficients None

$C_{p} \quad$ Pressure Coefficient None

$C_{V *} \quad$ Modified Velocity Coefficient None

$C_{V} \quad$ Velocity Coefficient None

$d x, d z$ Axial and vertical distance from wing leading edge to nacelle trailing edge m

$F_{G} \quad$ Gauge Stream Force kN

$F_{N} \quad$ Standard Net Thrust $\quad \mathrm{kN}$ 
$F_{s} \quad$ Specific Thrust

$N s k g^{-1}$

GPF Gross Propulsion Force

$\mathrm{kN}$

$G P F_{*}$ Modified Gross Propulsion Force

$\mathrm{kN}$

$P \quad$ Total pressure

$\mathrm{Pa}$

$p \quad$ Static pressure

Pa

$R \quad$ Universal Gas Constant

$J K^{-1} \mathrm{~mol}^{-1}$

$T \quad$ Total temperature

K

V Velocity

$m s^{-1}$

$y^{+} \quad$ Non-dimensional wall distance

None

k Turbulent Kinetic Energy

$J k g^{-1}$

\section{Greek Symbols}

$\Delta \quad$ Change due to installation None

$\gamma \quad$ Ratio of specific heats None

$\omega \quad$ Specific dissipation $\quad m^{2} s^{-2} k g^{-1}$

$\phi \quad$ Surface force $\quad$ N

$\rho \quad$ Density $\mathrm{kgm}^{-3}$

$\tau_{w} \quad$ Surface shear force $\quad$ N

$\theta \quad$ Thrust force $\quad$ N 


\section{Superscripts and Subscripts}

()$^{\text {Ideal }}$ At ideal isentropic conditions

()atm At freestream infinity

() critical At choking conditions

\section{Acronyms}

AIAA American Institute of Aeronautics and Astronautics

BPR Bypass Ratio

CFD Computational Fluid Dynamics

CNPR Core Nozzle Pressure Ratio

CRM Common Research Model

FNPR Fan Nozzle Pressure Ratio

FPR Fan Pressure Ratio

GEMINI Geometric Engine Modeller Including Nozzle Installation

LPT Low Pressure Turbine

MFCR Mass Flow Capture Ratio

OPR Overall Pressure Ratio

RANS Reynolds Average Navier Stokes

SFC Specific Fuel Consumption 


\section{SST Shear Stress Transport}

\section{Introduction}

\subsection{Background}

The next generation of large turbofan engines are expected to operate with higher bypass ratios (BPR) [1], low Fan Pressure Ratios (FPR) and low specific thrust $\left(F_{s}\right)$ in order to increase propulsive efficiency and hence reduce specific fuel consumption (SFC) [2]. Values of BPR for future turbofan aero-engines are expected to lie between 14 and 21 [3] compared with current generation turbofan engines which have BPRs between 9 and 11 [4]. Similarly, for conventional civil fans a design FPR can be expected to lie between 1.6 to 1.8 [5] and FPR values can be expected to be as low as 1.4 for ultra-high BPR engines [6]. An increase in bypass ratio can be achieved through the reduction of the core mass flow, an increase in bypass mass flow or through a combination of both. However, the reduction of core mass flow is somewhat limited and it is predicted that the increase in BPR will be mostly achieved through larger bypass mass flows [3]. As a result, engines will need to incorporate larger fan diameters in order to pass the increased total engine mass flow. With increased engine mass flows there follows a concurrent increase in inlet momentum drag. For a given net thrust, this must be compensated by an increase in gross thrust. As the ratio between the gross and net thrust increases, losses in the exhaust system could limit potential SFC improvements. Therefore, it is imperative that future engine 
configurations incorporate more aerodynamically efficient exhaust systems in order to meet the demand for reduced engine SFC.

\subsection{Exhaust system design}

The primary purpose of an exhaust system is to generate thrust whilst minimising the loss of total pressure [7]. The velocity and discharge coefficients are two non-dimensional performance metrics which are commonly used to quantify the aerodynamic performance of an exhaust system. The velocity coefficient is a measure of the thrust lost due to non-isentropic flow features. Reductions in the nozzle mass flow rate due to boundary layer growth, total pressure losses, flow blockage, and flow suppression are accounted for by the discharge coefficient. Furthermore, operability of the engine is ensured by an exhaust system which allows the desired fan and Low Pressure Turbine (LPT) exit flow capacities to be met [8]. If, due to installation onto the aircraft, the required mass flows are not met the engine may be forced to operate away from the design point. In order to compensate for any incompatible mass flows, the nozzle throat areas are often increased or decreased accordingly. However, knowledge of aircraft installation effects can help mitigate large modifications to the nozzle design late in the design process.

\subsection{Installation Aerodynamics}

The installation of conventional podded underwing engines is known to be detrimental to aircraft drag: typically between 30 and 50 drag counts per two engines [9], with the relative engine size and axial position identified as key 
performance sensitivities[10-12]. As a result of larger fan diameters, aerodynamic interference between the engine and airframe is expected to become a more significant consideration [13]. In some cases installation effects can be strong enough to outweigh the benefits of increased BPR [3]. However, there is a dearth of literature which is focused on the effect of engine-airframe integration on engine performance. Such installation effects are manifested through changes in nacelle drag, variations in gross thrust and core mass flow rate [14]. Given that higher BPR engines will be more sensitive to changes in gross thrust, the integration of the engine onto the airframe should aim to minimise thrust loss and hence any adverse effects onto the exhaust system.

\subsection{Determination of in-flight thrust}

In addition to the direct impact of exhaust system performance on engine SFC, nozzle performance metrics are also important due to their key role in the determination of thrust and drag in-flight [15]. For practical reasons, the direct measurement of thrust in flight is not yet feasible [16]. Although research has been undertaken in that domain [17], it is common practice for thrust to be deduced indirectly from engine operating parameters and drag determined by equating it to the thrust required for steady level flight $[16,18]$. One method for the measurement of gross thrust in-flight is to measure the total pressure at the inlet to each nozzle duct, calculate the ideal isentropic thrust and determine the gross thrust through the multiplication of the isentropic thrust by a velocity coefficient evaluated from a static ground test [18]. However, this method works under the assumption that the velocity and discharge coefficients do not vary between static calibration tests and flight conditions. Therefore, knowledge of the difference between installed 
and isolated nozzle performance metrics is required to ensure the correct prediction of in-flight thrust.

For computational studies which model exhaust jets, as opposed to throughflow nacelles (TFN), the net propulsive force of the configuration can be readily determined from numerical simulations [19]. However, there are multiple methods to distinguish between thrust and drag [19]. Such thrust and drag extraction methods can be split into two categories: far-field extraction methods [19-24] and near-field extraction methods [25-28]. Several studies have compared far-field and near-field methods for the prediction of airframe drag, with a difference in the order of 10-20 airframe drag counts between the two methods [20,23].

\subsection{Scope of Work}

For the proposed benefits of higher BPR engines to be realized it is vital that further research be conducted into the effects of engine-airframe integration on exhaust system performance. This work approaches engine installation with an engine centred view on aircraft installation effects. Although previous work has assessed the effect of installation on the net propulsive force generated by the engine [14, 29-31], it is necessary to understand how each engine subsystem performs upon installation. The exhaust system of high bypass ratio engines is of particular importance as, due to an increased ratio between gross and net thrust, losses in the exhaust system will have a greater effect on engine SFC compared to lower bypass ratio engines. Furthermore, with the expected increase to engine fan diameters, future propulsion systems will be more closely integrated to the airframe; therefore the effects of installation on the exhaust system need to be understood in order to produce 
an optimal engine-airframe system.

The research aim of this paper is to complete a numerical study in order to assess how a podded underwing aircraft installation alters the aerodynamic performance of the exhaust system. The specific novel contributions of this work are: the quantification of changes to exhaust system performance due to underwing installation; the identification of key aerodynamic features which govern the behaviour of installed aero-engine exhaust systems and the assessment of how engine architecture impacts installed exhaust system performance.

\section{Methodology}

The methodology set out to achieve these objectives can be broken into four sections: firstly, a description of the airframe and installation positions to be investigated is presented. This is then followed by an overview of the thermodynamic and aerodynamic design of the two engines to be investigated. Thirdly, the thrust and bookkeeping system and aerodynamic performance metrics are defined. Finally, details of the computational grid generation and numerical method are presented.

\subsection{Airframe and Installation Positions}

The airframe used in this study is the NASA Common Research Model (CRM) which was designed to represent a wide body civil transport aircraft capable of carrying 250-300 passengers [32]. Specifically, the wing/body/horizontaltail geometry [33] from the fourth Drag Prediction Workshop was used. The operating condition for this study corresponds to an altitude of $35,000 \mathrm{ft}$, a 
Mach number of 0.82 and a lift coefficient of 0.5. Although the CRM airframe was designed to cruise at a Mach number 0.85, a Mach number of 0.82 was chosen in order to avoid adverse drag characteristics that arose due to a corner separation at the wing fuselage junction at a freestream Mach number of $0.85[34,35]$. A lift coefficient of 0.5 was selected as this is the nominal design condition of the CRM airframe [32]. Moreover, a range of engine po-

sitions under the CRM wing were investigated with the relative position of the fan cowl trailing edge to the wing leading edge the defining parameter (Figure 1). The spanwise location of the engine was held constant. The axial distance from the wing leading edge to the trailing edge of the nacelle, $d x / c$, varied from 0.05 to 0.35 and the vertical position from the wing leading edge to the nacelle trailing edge, $d z / c$ varied from 0.07 to 0.22 (Figure 1 ). Within this scoping study, across a wide range of engine installation positions, the engine pylon was not modelled as a bespoke pylon design would have been required for each engine position. Such a design exercise is beyond the scope of this study.

\subsection{Thrust and Drag Accounting}

A thrust-drag bookkeeping method must be established to determine the correct division of losses between the airframe and engine. Although the net effect of installation is not affected by the division of thrust and drag, without a correct split the losses within the system will not be allocated correctly. Within this research the effect of installation on the airframe is not considered, instead the focus is on engine exhaust performance, i.e. the thrust domain. The effect of installation to the drag domain and cruise fuel burn is reported by Stańkowski et al.[14, 29, 30]. 
The thrust and drag bookkeeping method and engine station numbering system (Figure 2) employed in this work were based upon an established method [16]. The symbols $\theta$ and $\phi$ denote wall forces that lie in the thrust and drag domains respectively. Each wall force was evaluated through the numerical integration of pressure and shear-stress terms along each viscous surface. The gauge stream force and mass flow rate at a given engine station (with the station number denoted as a subscript) are represented by the symbols $F_{G}$ and $\dot{m}$. The ideal fully-expanded jet velocity is denoted with the symbol $V^{\text {ideal }}$ (Eq. 1 from [36]). Note that the superscript $D$ denotes that a force has been resolved into the $\hat{\mathbf{e}}_{D}$ direction (which is aligned with the drag axis as shown in Figure 2).

The velocity coefficient, $C_{V}$ in Eq. 2, is defined as the ratio of the actual gross propulsive force, $G P F^{D}$ in Eq. 3, generated from a nozzle to the thrust which be obtained if the core and fan streams were to expand isentropically to the atmospheric static pressure. The modified velocity coefficient, $C_{V}^{*}$ in Eq. 4, is defined as ratio of the modified gross propulsive force, $G P F_{*}^{D}$ in Eq. 5, to the ideal isentropic reference thrust. The velocity coefficient serves to quantify the nozzle performance within the ducts whereas the modified velocity coefficient accounts for both the internal nozzle and the external afterbodies. 


$$
\begin{gathered}
V^{\text {ideal }}=\sqrt{\frac{2 \gamma R T}{(\gamma-1)}\left(1-\left(\frac{1}{N P R_{p}}\right)^{\frac{\gamma-1}{\gamma}}\right)} \\
C_{V}^{D}=\frac{G P F^{D}}{\dot{m}_{7} V_{9}^{\text {ideal }}+\dot{m}_{13} V_{19}^{\text {ideal }}} \\
G P F^{D}=F_{G 19}^{D}+F_{G 9}^{D} \\
C_{V *}^{D}=\frac{G P F_{*}^{D}}{\dot{m}_{7} V_{9}^{\text {ideal }}+\dot{m}_{13} V_{19}^{\text {ideal }}} \\
G P F_{*}^{D}=F_{G 19}^{D}+F_{G 9}^{D}+\theta_{c c}^{D}+\theta_{p l u g}^{D}
\end{gathered}
$$

At cruise conditions the net propulsive force $\left(N P F^{D}\right.$, Eq. 6) quantifies the overall aerodynamic performance of the engine. However, as the nozzle discharge coefficients and mass flow rates are not known a priori, mass flow continuity between the intake and nozzles cannot be guaranteed in the CFD simulation. As such a corrected net propulsive force $\left(N P F_{c}^{D}\right.$, Eq. 7$)$ has been defined where the modified gross propulsive force of the engine was calculated for fixed nozzle mass flow rates. This correction was made based on the value of $C_{V *}^{D}$ calculated from each Computational Fluid Dynamic (CFD) solution and the nozzle mass flow rates $\left(\dot{m}_{7}^{\text {Cycle }}\right.$ and $\left.\dot{m}_{13}^{\text {Cycle }}\right)$ required by the $0 \mathrm{D}$ cycle analysis (Section 2.3 ). The standard net thrust $\left(F_{N}\right)$ of a separate-jet aero-engine is given by Eq. 8 . 


$$
\begin{gathered}
N P F^{D}=G P F_{*}^{D}-F_{G 0}^{D}-\left(\phi_{\text {pre }}^{D}+\phi_{\text {cowl }}^{D}\right) \\
N P F_{c}^{D}=C_{V *}^{D}\left(\dot{m}_{7}^{C y c l e} V_{7}^{\text {ideal }}+\dot{m}_{13}^{C y c l e} V_{13}^{\text {ideal }}\right)-F_{G 0}^{D}-\left(\phi_{\text {pre }}^{D}+\phi_{\text {cowl }}^{D}\right) \\
F_{N}^{D}=F_{G 19}^{D}+F_{G 9}^{D}-\dot{m}_{2} V_{0}
\end{gathered}
$$

A discharge coefficient is defined as the ratio of the actual mass flow rate that flows through a nozzle to the ideal mass flow rate which would flow through the nozzle which expands to the ambient static pressure under isentropic conditions $\left(C_{d}=\frac{\dot{m}}{\dot{m}^{I d e a l}}[36]\right)$. The operating point of each exhaust nozzle is characterized by the nozzle pressure ratio $\left(N P R=\frac{P}{p_{a t m}}\right)$ which is defined as the ratio between the total pressure at the inlet of the nozzle, $P$, and the atmospheric static pressure, $p_{a t m}$. As separate-jet nozzles are considered in this work, there are two nozzle pressure ratios of interest. The fan nozzle pressure $(F N P R)$ and the core nozzle pressure ratio $(C N P R)$. Note that the FNPR and CNPR are used in Eq. 1 to determine the ideal fully expanded jet velocity.

\subsection{Engine Geometry and Design}

To investigate the aerodynamic performance of aero-engine exhaust nozzles an appropriate engine cycle must be defined. Within the context of this work, the primary purpose of the engine cycle analysis is to provide boundary conditions for the CFD calculations as well as to provide initial estimates for the engine standard net thrust and SFC. The boundary conditions derived from the cycle analysis consisted of the intake mass flow rate $\left(\dot{m}_{2}\right)$, nozzle pressure ratios at cruise $(F N P R$ and $C N P R)$ and the total temperatures 
at the fan face, bypass inlet and core inlet $\left(T_{2}, T_{13}\right.$ and $T_{7}$ respectively). The engine cycles presented within this study were modelled with the zerodimensional (0D) modular gas turbine performance code Turbomatch [37].

Two engine cycles were examined in this study, which were developed as part of a previous installation study by Stańkowski et al . [29], each engine featured a standard net thrust requirement (Eq. 8) constant across both cycles of $55.7 \mathrm{kN}$. This requirement was set by the drag of the CRM configuration at the chosen operating condition and lift coefficient of 0.5 . The operating point of the cycle for Engine 1 (E1) was based upon open source estimations of engines of a similar thrust class and technology level i.e. a BPR of 11, an Operating Pressure Ratio (OPR) of 50 and Mass Flow Capture Ratio $(M F C R$ ) of 0.75 (Table 1). Engine 2 (E2) features a fan diameter which is $23 \%$ larger than that of E1 so that the installation effects due to increased fan diameters and lower engine specific thrust could be determined. Such an increase in fan diameters between the two engines is representative of change from a large to very large turbofan engine [6]. For the E2 engine, the aerodynamic operating point, cruise altitude Mach number and mass flow capture ratio (MFCR), were kept the same as for E1, with the OPR and BPR determined by optimising the cycle with the objective function to meet the $F_{N}$ requirement and minimise SFC. The resultant cycle demonstrates the expected engine design trends, i.e. an increased fan diameter and BPR, and reduction in FPR (Table 1). A BPR of 17.8 is representative of a future very large turbofan engine based on the preliminary study of Daggett [3] as well as the ENOVAL ultra high bypass ratio study [6]. Within the engine cycle context the FPR is defined as the ratio between the total pressure at the 
inlet of the bypass nozzle to the total pressure at the fan face $\left(\frac{P_{13}}{P_{2}}\right)$.

Table 1: Summary of cycle parameters for Engine (E1) and Engine 2 (E2) at cruise conditions

\begin{tabular}{lcc}
\hline & Engine 1 (E1) & Engine 2 (E2) \\
\hline Altitude & \multicolumn{2}{c}{$35,000 \mathrm{ft}$} \\
Cruise Mach Number & \multicolumn{2}{c}{0.82} \\
$M F C R$ & \multicolumn{2}{c}{0.75} \\
$F_{N}$ & \multicolumn{2}{c}{$55.7 \mathrm{kN}$} \\
Fan Diameter (relative to E1) & 1.0 & 1.23 \\
$B P R$ & 10.7 & 17.8 \\
Cruise FNPR & 2.7 & 2.1 \\
Cruise $C N P R$ & 1.4 & 1.7 \\
$O P R$ & 50 & 57 \\
$F P R$ & 1.67 & 1.4 \\
$F_{s}($ as a ratio of E1) & 1.0 & 0.66 \\
\hline
\end{tabular}

Axisymmetric engine geometries for the above engine cycles were created using a design tool named Geometric Engine Modeller Including Nozzle Installation (GEMINI)[36, 38, 39]. GEMINI implements a generic design approach which is applicable to a wide range of civil aero-engine separate-jet exhausts. Given a thermodynamic engine cycle and a set of engine geometry hard points a complete separate-jet geometry can be produced using class shape transformation curves [36, 38, 39]. For the E1 engine, preliminary design guidelines were used to determine the engine key points with the nozzle exit areas sized based on the flow capacity required from the engine cycle. For the E2 engine, the key engine hard points from the E1 engine were scaled by a factor of 1.23, except for the nozzle exit areas which were sized based upon the flow capacity requirement from the E2 cycle. 


\subsection{Grid Generation and Computational Domain}

The computational domain for all aircraft studies consisted of a hemispherical fluid domain with a pressure far-field boundary condition used to model the freestream conditions (Figure 3a). The diameter of this hemispherical domain was chosen to be 100c based on the findings of the well established AIAA Drag Predication Workshop [33]. The freestream Mach number was set to 0.82 in accordance with the operating point of this study and a range of freestream angles of attack $(\alpha)$ from 0 to $4^{o}$ were computed. This angle of attack was defined relative to the fuselage centreline. The engine fan face was modelled as a pressure outlet boundary condition (Figure 3a) with a target mass flow set according to the required operating point (Table 1). Pressure inlet boundary conditions were used to model the inlet of the bypass and core ducts (Figure 3a) with the values of total pressure and total temperature set based on the engine cycle. All airframe and engine surfaces were modelled as adiabatic and viscous no-slip walls.

The installed configuration was meshed using a fully structured multiblock approach with the resultant mesh designed for full boundary layer resolution with a $y^{+}<1$. An example of the surface mesh is presented in (Figure 3b). The blocking strategy and meshing guidelines for the intake, nacelle and aircraft were determined from domain and mesh independence studies and validated against experimental data by Stańkowski [25]. Similarly, the exhaust system meshing guidelines outlined by Stańkowski [29] were validated against experimental data and verified by Otter et al. [40]. For the installed engine studies the resultant mesh consisted of 35 million elements. For the isolated engine the same boundary conditions and mesh- 
ing guidelines for the installed engine configuration were used. The mesh for the isolated engine consisted of 10 million elements. Furthermore, a domain and mesh study for the aforementioned isolated engine has been reported by Stańkowski [29].

\subsection{Computational Method}

An implicit density based compressible solver [41] was used to solve the Reynolds-averaged Navier-Stokes (RANS) equations such that the aerodynamic performance of each engine-airframe configuration could be assessed. The computational method used within this work has been validated for the calculation of transonic aircraft performance by Stańkowski et al. [25] and similarly for the calculation of exhaust system performance by Otter et al [40]. The equations for continuity, momentum, energy, turbulent kinetic en-

ergy and specific turbulent dissipation rate were discretised with a second order upwind spatial scheme. The Roe Flux-difference splitting scheme was used to evaluate the inviscid flux vector and gradients were computed with Green-Gauss node based discretisation [42, 43]. The $k-\omega$ Shear Stress Transport (SST) turbulence model [44] was used to close the RANS equations based on the outcome of the validation studies for both the aircraft and isolated separate jet configurations.

Throughout each numerical solution residuals of velocity, continuity, energy, turbulent kinetic energy and specific turbulent dissipation rate were monitored. Iterative convergence achieved through a gradual increase of the Courant-Friedrichs-Lewy (CFL) number throughout the solution from 1 to 50 until the aforementioned residuals decreased by at least three orders of magnitude. A typical residual convergence plot for a single incidence is shown 
in Figure 4. A sweep of 8 incidence angles from 0 to $4^{\circ}$ took 128 hours when computed across 48 Intel E5-2660 Sandy Bridge CPUs. The working fluid of air was modelled as an ideal gas in tandem with an 8th order polynomial expression for specific heat capacity as a function of static temperature [45]. Thermal conductivity was modelled according to kinetic theory. Finally, Sutherland's law was used for the calculation of dynamic viscosity [46].

\section{Results and Discussion}

The aim of this section is to quantify the sensitivity of the modified nozzle performance metrics to engine installation position and aircraft incidence. The aerodynamic features which govern the exhaust system performance are identified and analysed with particular attention paid to differences in the behaviour of the two engines which arise. Firstly, detailed of the validation and verification of the computational approach are reported. Secondly, the effect of engine position at cruise conditions is presented and finally the variation of nozzle performance with aircraft incidence is considered.

\subsection{Validation and Verification}

The computational approach used within this study has been validated against experimental data for the calculation of aircraft [25] and nacelle per-

formance [47]. The drag calculated based on the computational approach which in agreement with experimental data to within $5 \%$ and $4 \%$ for the airframe [25] and nacelle [47] respectively. Furthermore, this approach was also shown to be valid for the calculation of the aerodynamic effects on an airframe that arise due to the presence of an underwing through-flow nacelle to within one drag count [25]. Mesh and domain independence studies for 
the isolated and installed configurations are reported by Stańkowski [29]. In terms of nozzle performance, the computational approach has been validated to calculate thrust coefficients, core and bypass coefficient to within $0.1 \%$, $0.4 \%$ and $0.3 \%$ of experimental data respectively [40].

\subsection{Effect of Engine Position at Constant Lift}

The results within this section consider how the engine installation location alters the aerodynamic performance of the exhaust system. In order to quantify the change in performance between the isolated and installed engines an installation delta, $\Delta(\%)=\frac{\text { installed-isolated }}{\text { isolated }}$, has been defined. Each installed coefficient is evaluated at an aircraft incidence $(\alpha)$ where the lift coefficient of the entire aircraft system is equal to 0.5 . The value of $\alpha$ at cruise conditions was determined through a piecewise polynomial interpolation of each metric as a function of $\alpha$. The change in cruise incidence was found to vary between $2.4^{\circ}$ and $2.5^{\circ}$ for the cases considered. The isolated metric was evaluated at a freestream incidence equal to the local flow angle at the centre of the installed engine highlight plane. This local flow angle was defined as the sum of the engine pitch angle, aircraft incidence and the local upwash angle. The positional variation of each metric is presented in the form of line contour plots with each CFD result denoted as a filled circle (Figures 5 and 8). The line contours, obtained from Kriging interpolation, are included for visualisation purposes only.

The dominant effect of installation on thrust generation is manifested through alterations to the core cowl and core plug afterbody forces. This is demonstrated through the variation of $\Delta C_{V *}^{D}$ with $d x / c$ and $d z / c$ (Figure 5). The E1 engine displayed a range of $\Delta C_{V *}^{D}$ of $0.75 \%$ to $-0.45 \%$ across the engine 
positions investigated (Figure 5a). Similarly, the E2 engine displayed a range of $\Delta C_{V *}^{D}$ from $0.6 \%$ to $-0.3 \%$ (Figure $5 \mathrm{~b}$ ). Both engines had a maximum value of $\Delta C_{V *}^{D}$ in position $\mathrm{A} 1(d x / c=0.35, d z / c=0.07)$ and minimum values in position $\mathrm{C} 3(d x / c=0.05, d z / c=0.17)$. At the closet axial position $(d x / c=0.05)$ a negative $\Delta C_{V *}^{D}$ was found in all vertical positions for both engines. The sensitivity of $\Delta C_{V *}^{D}$ to horizontal positional for both engines was found to be greater in row $1(d z / c=0.07)$ compared with rows 2 and $3(d z / c=0.07$ and 0.17$)$. Although there are differences in peak values of $\Delta C_{V *}^{D}$, the shape of the maps are consistent between the two engines, this suggests that the aerodynamic mechanism which governs the behaviour of installed $C_{V *}^{D}$ is consistent between the two engines.

In order to place these results into context it is necessary to consider the impact that variations in $C_{V *}^{D}$ have on the corrected engine net propulsive force $\left(N P F_{c}^{D}\right.$ defined in Eq. 7). A quantification for this relationship can be made by assessing the linear correlation of $N P F_{c}^{D}$ and $C_{V *}^{D}$ for each set of horizontal engine locations (Figure 6 and Table 2). Table 2 details how the gradient of $N P F_{c}^{D}$ with $C_{V *}^{D}$ varies for each set of horizontal engine positions. The value of the gradient $\frac{d N P F_{c}^{D}(\%)}{d C_{V *}^{D}(\%)}$ in Table 2 quantifies how $N P F_{c}^{D}$ will alter due to a $1 \%$ change in $C_{V *}^{D}$. The $N P F_{c}^{D}$ of both the E1 and E2 engines displays the greatest sensitivity to $C_{V *}^{D}$ when positioned in the closest axial positions (column $\mathrm{C}$ with $d x / c=0.05$ ). In each of the installation columns the $N P F_{c}^{D}$ of the E2 engine displayed a greater sensitivity to the modified velocity coefficient compared to the E1 engine. Hence, it is possible to conclude that although both engines displayed similar variation to $C_{V *}^{D}$ due to installation, the impact this has on $N P F_{c}^{D}$ is different for the two 
Table 2: Sensitivity of Net Propulsive Force to modified velocity coefficient with engine position

\begin{tabular}{lcc} 
Axial Position & $\frac{d N P F_{c}^{D}(\%)}{d C_{V *}^{D}(\%)} \mathrm{E} 1$ & $\frac{d N P F_{c}^{D}(\%)}{d C_{V *}^{D}(\%)} \mathrm{E} 2$ \\
\hline $\mathrm{A}(d x / c=0.35)$ & 1.3 & 3.5 \\
$\mathrm{~B}(d x / c=0.20)$ & 2.4 & 3.9 \\
$\mathrm{C}(d x / c=0.05)$ & 7.1 & 21.7 \\
\hline
\end{tabular}

engines. In particular it should be noted that the E2 engine, which features a lower specific thrust than the E1 engine, displayed a greater variation in $N P F_{c}^{D}$ than the E1 engine. Furthermore, this analysis demonstrates that variations to the $C_{V *}^{D}$ lead to substantial changes to the engine $N P F_{c}^{D}$.

To understand the origins of the variations in $\Delta C_{V *}^{D}$ it is necessary to examine the variation of static pressure $\left(C_{p}\right)$ along the core cowl afterbodies for the two engines (Figure 7). As the E1 engine operates at a higher FNPR than the E2 engine (2.7 compared to 2.1) a more pronounced set of expansion and compression waves in the bypass jet over the E1 core cowl afterbody are observed compared to the E2 core cowl afterbody (Figures 7a and 7c).

When installed in position $\mathrm{C} 3(d x / c=0.05, d z / c=0.17)$ both engines display a minimum value of $C_{p}$ at the inboard sideline (as shown by the $-90^{\circ}$ line in Figures $7 \mathrm{a}$ and $7 \mathrm{c})$. However, when installed in position A1 $(d x / c=$ $0.35, d z / c=0.07)$ the minimum value of $C_{p}$ occurs on the bottom line (as shown by the $180^{\circ}$ line in Figures $7 \mathrm{~b}$ and $7 \mathrm{~d}$ ) for E1 and outboard side line $\left(90^{\circ}\right)$ for $\mathrm{E} 1$. This variation in $C_{p}$ arises due to aerodynamic interaction between the lower surface of the wing and the exhaust afterbodies. With the engine installed in position C3, the inboard side of the core cowl is subject to greater suction than the outboard side as the inboard side of the afterbody overlaps with the swept wing. However, when the engine is positioned further 
upstream the afterbody is no longer overlapped with the wing and instead the pressure signature of the wing is projected onto the inboard side of the core cowl. In general, more positive values of $C_{p}$ are observed for both engines when installed in position A1 compared to C3. When integrated over the entire core cowl afterbody, this increased $C_{p}$ produces an increase in thrust generation and hence an increase in $\Delta C_{V *}^{D}$.

For the E1 engine a negative $\Delta C_{d}^{C o r e}$ was observed across all of the installation positions (Figure 8a) with the largest $\Delta C_{d}^{\text {Core }}$ found in position A1 (Figure 8a). The value of $\Delta C_{d}^{\text {Core }}$ ranged from $-2 \%$ to $-10 \%$ for E1 (Figure 8a) and from $0.75 \%$ to $-1.0 \%$ for E2 (Figure $8 b$ ). For the E2 engine a negative $\Delta C_{d}^{\text {Core }}$ was observed for all positions except those in column C (Figure 8b). In terms of installed $C_{d}^{C o r e}$ the highest value would be obtained in position $\mathrm{C} 3$ for both engines. The sensitivity of $\Delta C_{d}^{C o r e}$ for $\mathrm{E} 2$ in the horizontal direction is greater than sensitivity to vertical location. This is shown by almost vertical contours in closet horizontal column (Figure 8b). Whereas E1 displays greater sensitivity to vertical position (Figure 8a). Such variations to $C_{d}^{\text {Core }}$ is an important aspect to consider as it affects the sizing of the core nozzle, the core mass flow rate and ultimately the engine operating point.

The aerodynamic mechanism which governs the behaviour of $C_{d}^{C o r e}$ arises due to the aircraft pressure field altering the effective pressure into which the core nozzle discharges into. Consider the E2 engine, when positioned in column $\mathrm{C}(d x / c=0.05)$ the engine is discharging into a pressure which is lower than isolated base pressure and as such more mass flow is discharged through the nozzle. Whereas when this engine is positioned in A1 $(d x / c$ $=0.35, d z / c=0.07)$, the base pressure is higher hence less mass flow is dis- 
charged. For example, at the trailing edge of the core cowl the value of $C_{p}$ can be seen to increase by 0.06 between position C3 and A1 (Figures 7c and $7 \mathrm{~d})$. The value of the static pressure at the trailing edge of the core cowl is indicative of the core nozzle base pressure. The case of the E1 is more complicated as a shock wave is present at the trailing edge of the core cowl topline $\left(0^{\circ}\right)$ for both positions $\mathrm{C} 3$ and A1 (Figures $7 \mathrm{a}$ and $7 \mathrm{~b}$ ). Between positions C3 and A1 the strength of this shock wave is shown to increase on the top line of the core cowl (as indicated by a larger increase of $C_{p}$ ). In position $\mathrm{A} 1$, this shock wave results in an increase of the static pressure at the trailing edge of the core cowl, and hence a reduction of the effective nozzle pressure ratio.

The variation of $C_{d}^{\text {Bypass }}$ with engine position was found to be less than $0.01 \%$ relative to the isolated engine at cruise conditions and as such it is not presented. This is to be expected as for both engines the bypass nozzle operates under choked conditions. Similarly, variations in velocity coefficient $\left(C_{V}^{D}\right)$ were found to be substantially smaller than the changes observed with modified velocity coefficient $\left(C_{V *}^{D}\right)$. This is due to the fact that $C_{V}^{D}$ only accounts for thrust generation up the nozzle throats, whereas $C_{V *}^{D}$ accounts for the thrust generation along the external afterbodies. For the E1 engine $\Delta C_{V}^{D}$ ranged from $0.2 \%$ to $-0.05 \%$ with installation position and similarly a range of $-0.05 \%$ to $-0.15 \%$ was found for the E2 engine. As the bypass nozzle is choked these changes in velocity coefficient only arise due to changes in core nozzle performance. A smaller variation of $\Delta C_{V}^{D}$ was found for E2 than was found for E1 as the E2 engine features a higher BPR and hence the core nozzle provides a smaller contribution to the gross propulsive force compared 
to the lower BPR E1 engine.

\subsection{Effect of Aircraft Incidence}

Within this section the effect of aircraft incidence on the nozzle performance metrics at a constant freestream Mach number is assessed. From the preceding section it was demonstrated that the presence of the wing has a significant impact upon the local static pressure field into which the exhaust system is discharged. It is therefore of interest to understand the sensitivity of the nozzle performance to the changes in lift and the associated wing pressure field that arise with variations to aircraft incidence. The variation of the modified velocity coefficient, engine thrust vector and core discharge coefficient is presented in Figure 9. Figures 9a and c show the effect on the aforementioned nozzle performance metrics with vertical offset $(d z / c$ from 0.07 to 0.17$)$ at a constant axial location $(d x / c$ equal to 0.05$)$. Moreover, Figures $9 \mathrm{~b}$ and $\mathrm{d}$ show the effect of varying axial location $(d x / c$ from 0.05 to $0.35)$ at a constant vertical offset $(d z / c$ of 0.07$)$.

For all of the engine positions investigated $\Delta C_{V *}^{D}$ was found to be an increasing monotonic function of $\alpha$ (Figures $9 \mathrm{a}$ and $\mathrm{b}$ ). With the engine in position $\mathrm{C} 3(d x / c=0.05, d z / c=0.17)$, the variation of $\Delta C_{V *}^{D}$ with $\alpha$ was very similar between both engines. For example, a range of $\Delta C_{V *}^{D}$ between $-1.7 \%$ and $0.3 \%$ for the $\mathrm{E} 1$ engine and $-1.6 \%$ and $0.15 \%$ for $\mathrm{E} 2$ engine was found over a incidence range of $0^{\circ}$ to $4^{o}$ (Figure $9 \mathrm{a}$ ). At $d x / c=$ of 0.05 (column $\mathrm{C}$ ) the sensitivity of $\Delta C_{V *}^{D}$ to aircraft incidence was found to increase slightly as the engine vertical offset is reduced (lines labelled C1, C2, and C3 in Figures 9a). Note that the position with the lowest value of vertical offset from the wing is $\mathrm{C} 1(d z / c=0.07)$ and the engine positioned 
furthest from the wing vertically is $\mathrm{C} 3(d z / c=0.17)$. However, at a constant $d z / c$ of 0.07 (positions $\mathrm{A} 1, \mathrm{~B} 1$, and $\mathrm{C} 1$ where $\mathrm{C} 1$ is positioned closest to the wing axially and A1 the furthest) increased axial distance from the leading edges reduces the variation of $\Delta C_{V *}^{D}$ with $\alpha$ (Figure 9b). For example, with the $\mathrm{E} 2$ engine located in position $\mathrm{A} 1(d x / c=0.35, d z / c=0.07)$ a change of $\Delta C_{V *}^{D}$ from $0.1 \%$ to $0.9 \%$, relative to the isolated engine, is observed between $\alpha$ values of $0^{\circ}$ and $4^{\circ}$, whereas in $\mathrm{C} 1(d x / c=0.05, d z / c=0.07)$ a similar change from $-1.7 \%$ to $0.2 \%$ is observed.

The modified velocity coefficient increases with aircraft incidence due to an increase of $C_{p}$ along the wing lower surface as $\alpha$ is increased. At low $\alpha$ a large region of low static pressure is present midway along the lower side of the wing (Figures 10a and c). As this region is in close proximity to the exhaust afterbodies it has the effect of reducing the static pressure, and hence thrust generation, on these surfaces. With increased incidence the pressure along the lower surface of the wing increases (Figures 10b and d) and generates additional thrust on the exhaust afterbodies.

The final performance metric to be presented as a function of aircraft incidence is the core discharge coefficient $\left(C_{d}^{C o r e}\right)$. Upon installation $\Delta C_{d}^{C o r e}$ for the E2 engine was found to decrease monotonically with $\alpha$ for all of the installation positions investigated (Figures $9 \mathrm{c}$ and $\mathrm{d}$ ). With the engine located in column $\mathrm{C}(d x / c=0.05) \Delta C_{d}^{C o r e}$ for the $\mathrm{E} 2$ engine was found to be insensitive to vertical position (Figure 9c). However, at a constant vertical position, increasing the horizontal offset was shown to reduce $\Delta C_{d}^{C o r e}$ (Figure $9 \mathrm{~d})$. In contrast to the $\mathrm{E} 2$ engine, a non-monotonic variation of $\Delta C_{d}^{\text {Core }}$ was observed with $\alpha$ for the E1 engine located in column $\mathrm{C}$ i.e. a $d x / c=0.05$ 
(Figure $9 \mathrm{c}$ ). With reduced values of $d z / c$ at a constant $d x / c$ value of 0.05 , the values of $\Delta C_{d}^{C o r e}$ can be seen to be offset relative to the C3 case (Figure 9e). However, a monotonic variation of $\Delta C_{d}^{\text {Core }}$ with angle of attack is observed with the same engine installed in positions B1 and A1 (Figure 9d).

As previously discussed, the non-monotonic behaviour of the E1 engine $C_{d}^{C o r e}$ can be attributed to the formation of a shock wave at the trailing edge of the core cowl. When the engine is installed in position $\mathrm{A} 1(d x / c=0.35$, $d z / c=0.07)$ across an incidence range of 0 to $4^{\circ}$ there is a normal shock wave present at the trailing edge of the core cowl (Figure 11b). As this shock is present across the entire range of incidences a monotonic reduction in $C_{d}^{\text {Core }}$ is seen with incidence. In contrast, with the $\mathrm{E} 1$ engine installed in position C3 $(d x / c=0.05, d z / c=0.17)$ a shock wave is not present at an $\alpha$ of $0^{\circ}$, but is present at incidences of $2.5^{\circ}$ and $4^{\circ}$ (Figure 11a). The formation of this shock wave changes the core nozzle base pressure and hence the $C_{d}^{\text {Core }}$ value. Furthermore, the variation of $C_{p}$ along the core cowl gives an indication as to why $C_{V *}^{D}$ for the $\mathrm{E} 1$ engine is more sensitive to incidence in position $\mathrm{C} 3$ compared to position A1. This is because a greater change in the bypass-jet expansion with $\alpha$ occurs in position $\mathrm{C} 3$ and hence there is a greater change in the integral of this $C_{p}$.

\subsection{Ramifications of Aircraft Installation for Exhaust System Design}

As outlined in the introduction, an exhaust system should be designed such that the desired flow capacities from the LPT and fan can be met. For the studied engine geometries and underwing engine positions investigated, it has been shown that at cruise conditions variations between -10\% and $1.3 \%$ can occur to $C_{d}^{C o r e}$ compared to an isolated engine. At a constant $C N P R$ this 
variation will directly correspond to a variation in core mass flow rate. This variation in core nozzle mass flow rate means that the core nozzle will either have to be resized for a given engine position, or that the LPT, and hence fan, would be forced to operate at off-design conditions. Furthermore, it has been shown, for the studied engine geometries and under-wing engine positions, that $C_{d}^{\text {Core }}$ can vary between $3.7 \%$ and $-13 \%$ over a range of aircraft incidences from $0^{\circ}$ to $4^{\circ}$. Hence, even if the core nozzle was resized to take into account installation effects at cruise conditions, with variations to incidence over the flight schedule the LPT operating point will be affected. With this in mind it is clear that aircraft installation effects on nozzle performance should be considered when exhaust system is designed such that variations in $C_{d}^{C o r e}$ with incidence, for a given engine position, are minimised. For example, the E1 core cowl design in this study has been shown to be particularly sensitive to installation position and incidence.

The performance of the core nozzle is the not the only reason why aircraft installation effects should be considered when the exhaust system is designed. From Section 3.2 the modified velocity coefficient $\left(C_{V *}^{D}\right)$ was found to vary by up to $1 \%$ with installation position. As this variation in $C_{V *}^{D}$ is governed by the static pressure distribution along the core cowl (Figure 7), then there exists a substantial argument that the core cowl design should be completed for a given installation position in order to ensure that the most efficient exhaust system is obtained. 


\section{Conclusions}

The effect of engine installation on exhaust system performance has been quantified for podded underwing installations and an assessment has been made of the sensitivity of the nozzle performance metrics to engine position and aircraft angle of attack for two engine architectures. Furthermore, the prevalent aerodynamic flow features of engine installation on the exhaust system were identified. The specific conclusions of this work are as follows:

1. Over the range of engine axial positions investigated $C_{V *}^{D}$ was found to vary by up to $1 \%$ relative to the value of the isolated value of $C_{V *}^{D}$ for both of the engines investigated. The interaction between the airframe wing and exhaust afterbodies was found to be beneficial or detrimental to $C_{V *}^{D}$ depending on the position of the engine relative to the wing leading edge.

2. The dominant installation effect was found to be due to the interaction between the airframe wing and engine exhaust system afterbodies. This variation in thrust generation due to the exhaust afterbodies occurred due to the variation of static pressure on both the core cowl and core plug induced by the presence of the aircraft wing.

3. Although the absolute values of changes to $C_{V *}^{D}$ were different for the two engines investigated, the trends observed for engine installation position were very similar. This indicates that changes in thrust generation due to installation is dominated by the wing pressure field rather than the nozzle operating point.

4. The engine net propulsive force was found to be more sensitive to variations to the modified thrust coefficient when the engine was positioned 
closest to the wing axially. Furthermore, across all of the installation positions examined the net propulsive force of the lower specific thrust engine was found to be more sensitive to the installed exhaust system performance than the higher specific thrust engine.

5. A variation of core discharge coefficient of up to to $10 \%$ was observed across the engine positions investigated. This effect was governed by the local static pressure into which the engine discharged into, which was a function of both engine position and aircraft incidence. Moreover, the characteristics of the bypass jet were found to have a strong influence on the core discharge coefficient.

Given the magnitude of the installation effects on exhaust performance, both in terms of core discharge coefficient and thrust generation, it is recommended that further research should be undertaken to account for installation effects as part of the engine cycle design in order to minimise any adverse effects on installed engine performance.

\section{Acknowledgments}

The doctoral studies of John Otter, Tomasz Stańkowski and Matthew Robinson were partially funded by Rolls-Royce plc. In addition, the Engineering and Physical Science Research Council partially funded John Otter's and Matthew Robinson's doctoral studies. Due to commercial confidentiality agreements the supporting data is not available. The authors would like

to thank J. C. Vassberg for making the geometry of the Common Research Model available. 


\section{References}

[1] Birch, N. T., "2020 vision: the prospects for large civil aircraft propulsion," The Aeronautical Journal, Vol. 104, No. 1038, pp. 347-352.

[2] Guha, A., "Optimum Fan Pressure Ratio for Bypass Engines with Separate or Mixed Exhaust Streams," Journal of Propulsion and Power, Vol. 17 (5), 2001, pp. 1117-1122.

[3] Daggett., D. L., Brown, S., and Kawai, R. T., "Ultra Efficient Engine Diameter Study," NASA-CR-2003-212309, 2003.

[4] Daly, M., Jane's Aero-Engines, IHS Jane's, 2010.

[5] Calvert, W. and Ginder, R., "Transonic fan and compressor design," Proceedings of the Institution of Mechanical Engineers, Part C: Journal of Mechanical Engineering Science, No. 5, 1999, pp. 419 - 436.

[6] "ENOVAL - Ultra High Bypass Ratio Aero Engines Technology Brochure," http://www.enoval.eu/media/mediablog/files/ ENOVAL_Final_Technology_Brochure_2018.pdf, Accessed on 29th January 2019.

[7] Mattingly, J. D., Elements of Gas Turbine Propulsion, McGraw-Hill, 2006.

[8] DeBonis, J. R., "Gas Turbine Engines: Nozzles," Encyclopedia of Aerospace Engineering, Vol. 1, 2010, pp. 1-11. 
[9] Hoheisel, H., "Aerodynamic Aspects of Engine-Aircraft Integration of Transport Aircraft," Aerospace Science and Technology, Vol. 7, 1997, pp. $475-487$.

[10] Brodersen, O., MEGAFLOW - Numerical Flow Simulation for Aircraft Design, Computation of Engine Airframe Installation Drag, Springer, 2005.

[11] Rossow, C. C., Godard, J., Hoheisel, H., and Schmitt, V., "Investigations of Propulsion Integration Interference Effects on a Transport Aircraft Configuration," Journal of Aircraft, Vol. 31, No. 5, 1994, pp. 1022-1030.

[12] Wiart, L., Atinault, O., Paluch, B., Hue, D., and Grenon, R., "Development of NOVA aircraft configurations for large engine integration studies," 33rd AIAA Applied Aerodynamics Conference, 2015, AIAA 2015-2254.

[13] Geyr, H. F. V. and Rosscow, C. C., "A Correct Thrust Determination Method For Turbine Powered Simulations in Wind Tunnel Testing," 41st AIAA/ASME/SAE/ASEE Joint Propulsion Conference 63 Exhibit, 2005, AIAA 2005-3707.

[14] Stańkowski, T. P., MacManus, D. G., Sheaf, C. T., and Grech, N., "Aerodynamics for Aero-engine Installation," 54th AIAA Aerospace Sciences Meeting, 2016, AIAA 2016-0764.

[15] Covert, E. E., James, C. R., Kimsey, W. M., Rickey, G. K., and Rooney, E., Thrust and Drag: Its Prediction and Verification (Progress in As- 
tronautics and Aeronautics Series), American Institute of Aeronautics and Astronautics, Reston, VA, 1985.

[16] MIDAP Study Group, "Guide to In-Flight Thrust Measurement of Turbojets and Fan Engines," AGARDograph No.237, Advisory Group for Aerospace Research and Development,Paris, 1979.

[17] Bauer, M., Friedrichs, J., Wulff, D., and Werner-Spatz, C., "Development and Validation of an On-Wing Engine Thrust Measurement System," ASME Turbomachinery Conference, 2017, GT2017-63277.

[18] ESDU, "The Determination of Gross Thrust and Mass Flow In Flight. (Air Breathing Ducted Flow Engines with Convergent Nozzles)," ESDU69007, 1981.

[19] Malouin, B., Gariepy, M., Trepanier, J.-Y., and Laurendeau, E., "Engine Pre-entry Thrust and Standard Net Thrust Evaluation Based on the Far Field Method," Aerospace Science and Technology, Vol. 45, 2015, pp. 5059.

[20] Destarac, D. and van der Vooren, J., "Drag/thrust Analysis of Jetpropelled Transonic Transport Aircraft; Definition of Physical Drag Components," Aerospace Science and Technology, Vol. 8 (7), 2004, pp. $545-556$.

[21] Malouin, B., Trepanier, J.-Y., and Laurendeau, E., "Installation and interference drag decomposition via RANS far-field methods," Aerospace Science and Technology, Vol. 54, 2016, pp. 132-142. 
[22] Malouin, B., Gariepy, M., Trepanier, J.-Y., and Laurendeau, E., "Internal Drag Evaluation for a Through-Flow Nacelle Using a Far-Field Approach," Journal of Aircraft, Vol. 52 (6), 2015, pp. 1847-1857.

[23] Vos, J. B., Sanchi, S., and Gehri, A., "Drag Prediction Workshop 4 Results Using Different Grids Including Near-Field/Far-Field Drag Analysis," Journal of Aircraft, Vol. 50 (5), 2013, pp. 1615-1627.

[24] Gariepy, M., Malouin, B., Trepanier, J.-Y., and Laurendeau, E., "Farfield Drag Decomposition Applied to the Drag Prediction Workshop 5 Cases," Journal of Aircraft, Vol. 50 (6), 2013, pp. 1822-1831.

[25] Stańkowski, T. P., MacManus, D. G., Sheaf, C. T., and Christie, R., "Aerodynamics of Aero-engine Installation," Proceedings of the Institution of Mechanical Engineers, Part G, Vol. 230, No. 14, 2016, pp. 26732696.

[26] Yuefi, Z., Haixin, C., Song, F., Miao, Z., and Meihong, Z., "Drag prediction method of powered-on civil aircraft based on thrust drag bookkeeping," Chinese Journal of Aeronautics, Vol. 28, No. 4, 2015, pp. 1023 $-1033$.

[27] Zhaoguang, T., Yingchun, C., and Jiangtao, S., "Study of Power Influences to the Wing-Mounted Civil Aircraft Aerodynamic Characteristics," Journal of Aircraft, Vol. 51 (2), 2014, pp. 629-636.

[28] Zheng, W., Wang, Y., Shan, J., Deng, X., and Tian, W., "Interference Mechanism of Engine Exhaust on Civil Aircraft Drag Performance," Journal of Aircraft, Vol. 49 (6), 2012, pp. 2001 - 2006. 
[29] Stańkowski, T. P., MacManus, D. G., Robinson, M., and Sheaf, C. T., "Aerodynamic Effects of Propulsion Integration for High Bypass Ratio Engines," Journal of Aircraft, Vol. 54 (6), pp. 2270-2284.

[30] Stańkowski, T. P., MacManus, D. G., Sheaf, C. T., and Grech, N., "Aerodynamic Interference for Aero-engine Installations," 54th AIAA Aerospace Sciences Meeting, 2016, AIAA 2016-0766.

[31] Sibilli, T., Savil, M., Sethi, V., MacManus, D., and Rolt, A., "Numerical Simulation of Propulsion Systems Integration For Very High Bypass Ratio Engines," Proceedings of ASME Turbo Expo GT2012, 2012, GT2012-68908.

[32] J. C. Vassberg et al., "Development of a Common Research Model for Applied CFD Validation Studies," 26th AIAA Applied Aerodynamics Conference, AIAA 2008-6919.

[33] Tinoco, E. N., Levy, D., and Brodersen, O., "AIAA 4th Drag Prediction Workshop," https://aiaa-dpw.larc.nasa.gov/Workshop4/ workshop4.html, 2009, Accessed on 13th April 2015.

[34] Sclafani, A., DeHaan, M., Vassberg, J., Rumsey, C., and Pulliam, T., "Drag Prediction for the NASA CRM Wing-Body-Tail Using CFL3D and OVERFLOW on an Overset Mesh," 28th AIAA Applied Aerodynamics Conference, 2010, AIAA 2010-4219.

[35] Illi, S. A., Fingskes, C., Lutz, T., and Kramer, E., "Transonic Tail Buffet Simulations for the Common Research Model," AIAA Applied Aerodynamics Conference, 2013, AIAA 2013-2510. 
[36] Goulos, I., Stańkowski, T., Otter, J., MacManus, D., Grech, N., and Sheaf, C., "Aerodynamic Design of Separate-Jet Exhausts for Future Civil Aero-engines Part I: Parametric Geometry Definition and Computational Fluid Dynamics Approach," Journal of Engineering for Gas Turbines and Power, Vol. 138(8), 2016, pp. 081201-1 to 081201-14.

[37] Macmillian, W. L., Development of a Module Type Computer Program for the Calculation of Gas Turbine Off Design Performance, Ph.D. Thesis, Department of Power and Propulsion, Cranfield University, 1974.

[38] Goulos, I., Otter, J., Stańkowski, T., MacManus, D., Grech, N., and Sheaf, C., "Aerodynamic Design of Separate-Jet Exhausts for Future Civil Aero-engines Part II: Design Space Exploration, Surrogate Modeling, and Optimization," Journal of Engineering for Gas Turbines and Power, Vol. 138(8), 2016, pp. 081202-1 to 081202-12.

[39] Goulos, I., Stańkowski, T., MacManus, D., Woodrow, P., and Sheaf, C., "Civil Turbofan Engine Exhaust Aerodynamic: Impact of Bypass Nozzle After-body Design," Aerospace Science and Technology, Vol. 73, 2017, pp. 85-95.

[40] Otter, J., Goulos, I., MacManus, D., and Slaby, M., "Aerodynamic Analysis of Civil Aero-Engine Exhaust Systems using Computational Fluid Dynamics," Journal of Propulsion and Power, 2017, (Article in Advance).

[41] Weiss, J. M., Maruszewski, J. P., and Smith, W. A., "Implicit Solution 
of the Navier-Stokes Equations on Unstructured Meshes," 13th Computational Fluid Dynamics Conference, 1997, AIAA 97-2103.

[42] Holmes, D. G. and Connell, S. D., "Solution of the 2D Navier-Stokes Equations on Unstructured Adaptive Grids," 9th Computational Fluid Dynamics Conference, 1989, AIAA 89-1932.

[43] Rauch, R. D., Batira, J. T., and Yang, N. T. Y., "Spatial Adaption Procedures on Unstructured Meshes for Accurate Unsteady Aerodynamic Flow Computations," 32nd Structures, Structural Dynamics, and Materials Conference, 1991, AIAA 91-1106.

[44] Menter, F. R., "Two-Equation Eddy-Viscosity Turbulence Models for Engineering Applications," AIAA Journal, Vol. 32 (8), 1994, pp. 15981605 .

[45] Walsh, P. and Fletcher, P., Gas Turbine Performance, Blackwell Publishing, Oxford, 2nd ed., 2004.

[46] Sutherland, W., "The Viscosity of Gases and Molecular Forces," Philsophical Magazine, Vol. 5 (36), 1893, pp. 507-531.

[47] Robinson, M., MacManus, D. G., and Sheaf, C., "Aspects of aero-engine nacelle drag," Proceedings of the Institution of Mechanical Engineers, Part G: Journal of Aerospace Engineering, 2018. 


\section{List of Figures}

1 Schematic of engine installation position and engine positions investigated in this study . . . . . . . . . . . . . 38

$2 \quad$ Schematic for the breakdown of Thrust and Drag . . . . . . 39

3 Definition of the computations domain and example of surface mesh . . . . . . . . . . . . . . 4 40

4 Example residual convergence for a single incidence . . . . . . 41

5 Positional variation of modified velocity coefficient relative to isolated engine at constant lift for a) E1 and b) E2. Dashed lines denote negative values. . . . . . . . . . . . . 42

6 Variation of engine net propulsive force and modified velocity coefficient for the E1 and E2 engine . . . . . . . . . . 43

7 Azimuthal Variation of Static Pressure along the core cowl at the topline $\left(0^{\circ}\right)$ outboard sideline $\left(90^{\circ}\right)$, bottomline $\left(180^{\circ}\right)$ and inboard side line $\left(-90^{\circ}\right)$ at cruise conditions. . . . . . . . . 44

8 Variation of installed core discharge coefficient relative to isolated engine at constant lift for a) E1 and b) E2. Dashed lines denote negative values. . . . . . . . . . . . . . . 45

9 Variation of nozzle performance metrics with aircraft incidence and engine position relative to isolated engine for a) and b) Modified velocity coefficient c) and d) core discharge coefficient 46

10 Variation of static pressure coefficient through the engine midsection for the E1 engine at a) $\alpha=0.0$ b) $\alpha=4.0$; the E2 engine at c) $\alpha=0.0$ and d) $\alpha=4.0$ in position $\mathrm{C} 3(d x / c=0.05$, $d z / c=0.17) \ldots \ldots \ldots \ldots \ldots \ldots \ldots \ldots$

11 Variation of static pressure along the E1 core cowl topline with airframe incidence. . . . . . . . . . . . . . . . . 48 


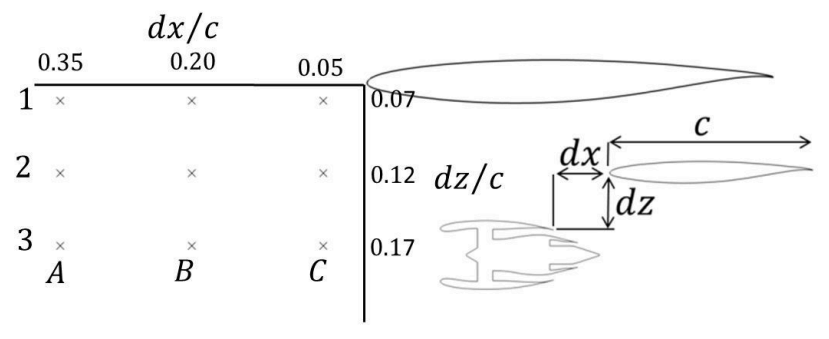

Figure 1: Schematic of engine installation position and engine positions investigated in this study 


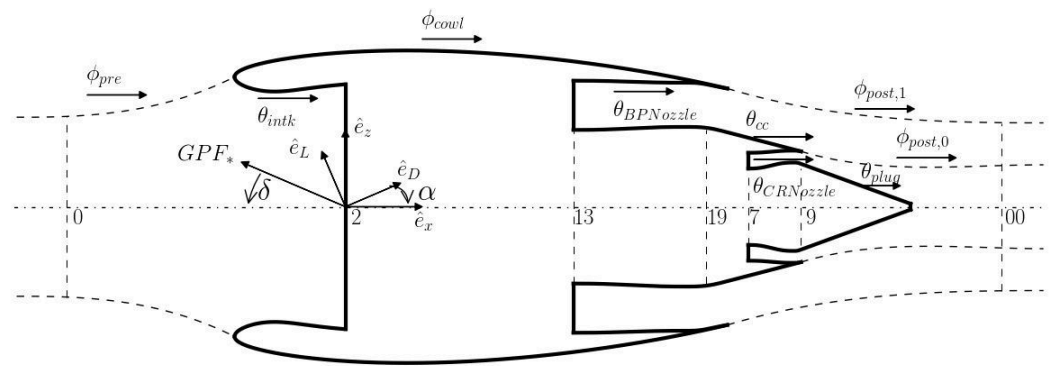

Figure 2: Schematic for the breakdown of Thrust and Drag 


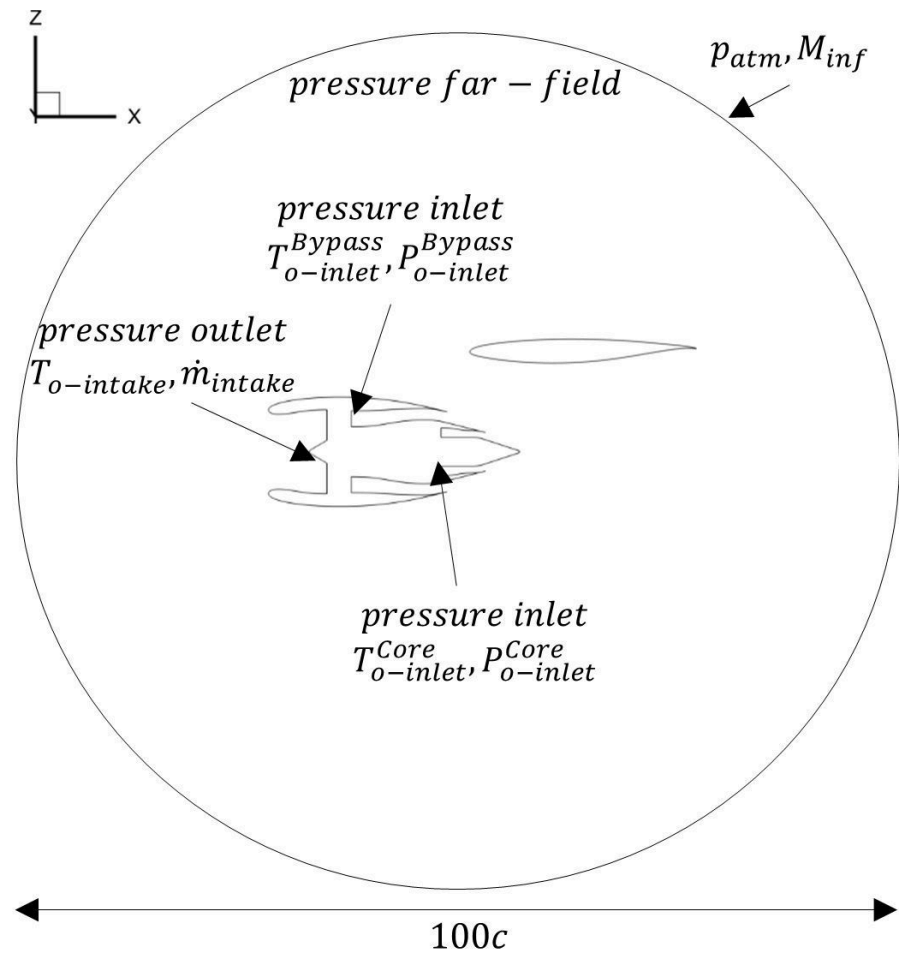

(a) Computation Domain and Boundary Conditions

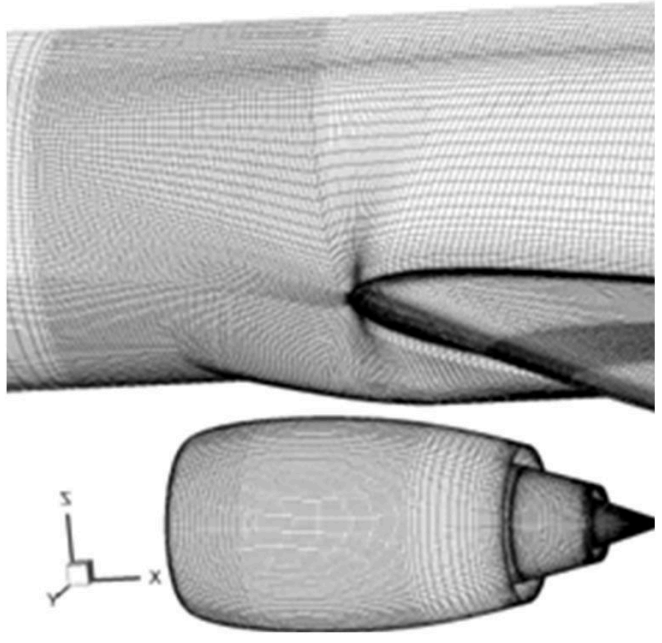

(b) Close up of surface mesh

Figure 3: Definition of the computations domain and example of surface mesh 


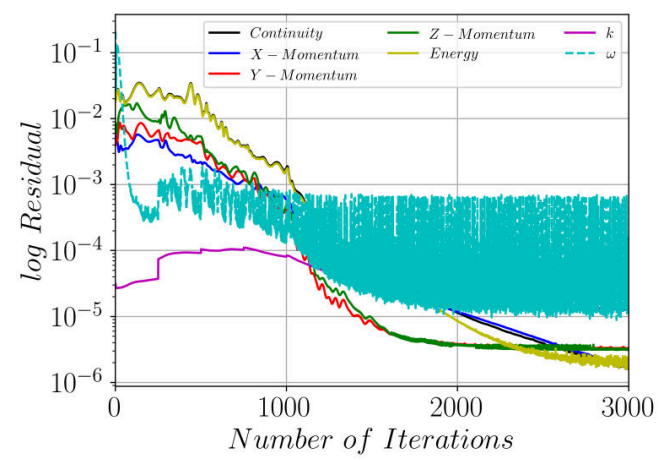

Figure 4: Example residual convergence for a single incidence 


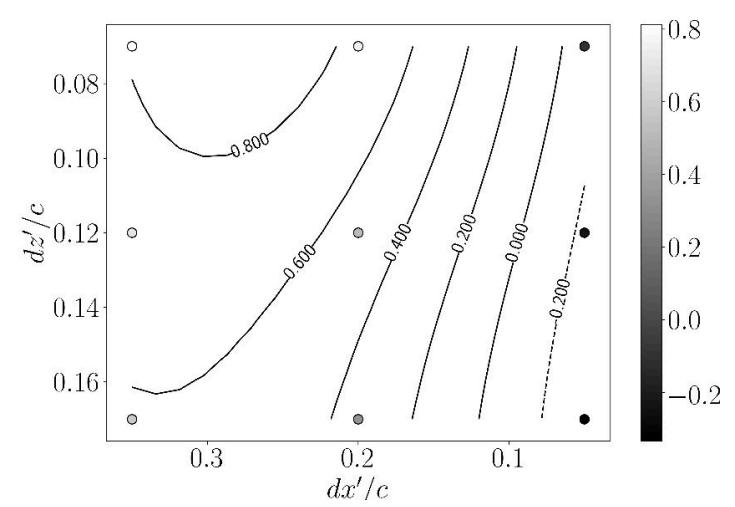

(a) $\mathrm{E} 1 \Delta C_{V *}^{D}(\%)$

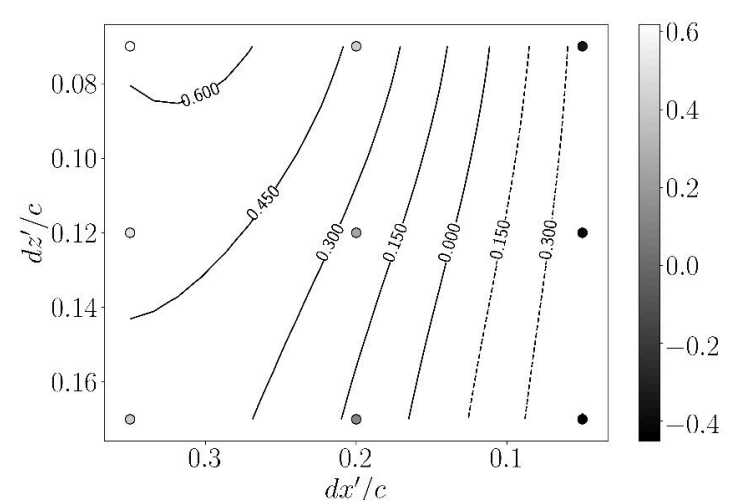

(b) E2 $\Delta C_{V *}^{D}(\%)$

Figure 5: Positional variation of modified velocity coefficient relative to isolated engine at constant lift for a) E1 and b) E2. Dashed lines denote negative values. 


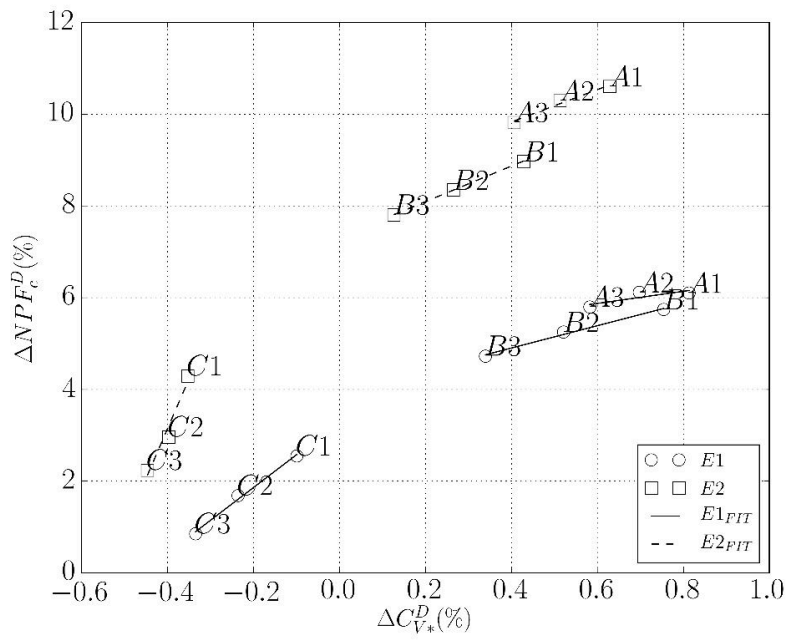

Figure 6: Variation of engine net propulsive force and modified velocity coefficient for the E1 and E2 engine 


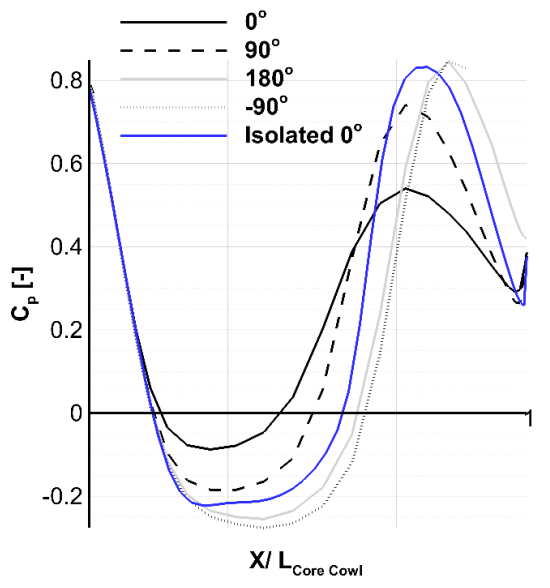

(a) E1 in position C3

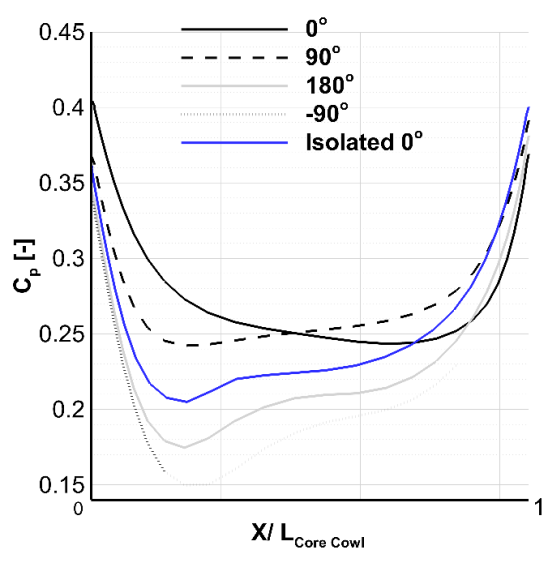

(c) E2 in position C3

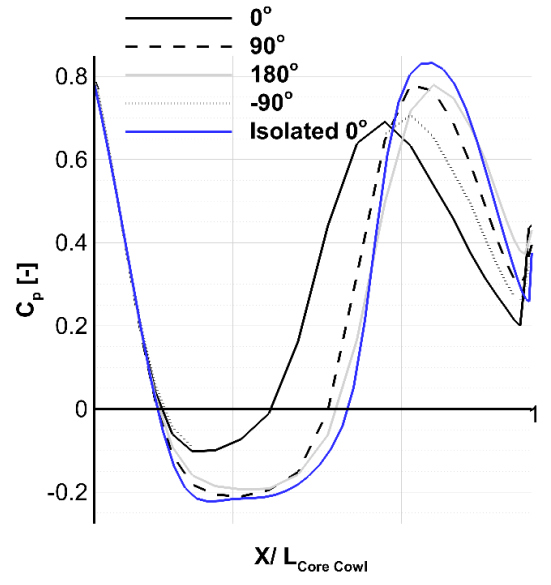

(b) E1 in position A1

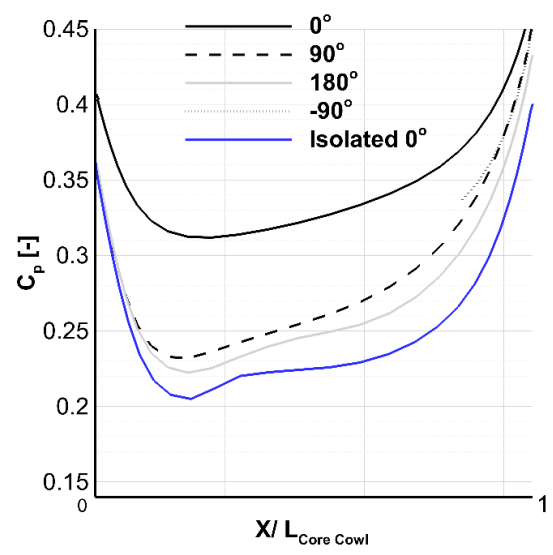

(d) E2 in position A1

Figure 7: Azimuthal Variation of Static Pressure along the core cowl at the topline $\left(0^{\circ}\right)$ outboard sideline $\left(90^{\circ}\right)$, bottomline $\left(180^{\circ}\right)$ and inboard side line $\left(-90^{\circ}\right)$ at cruise conditions. 


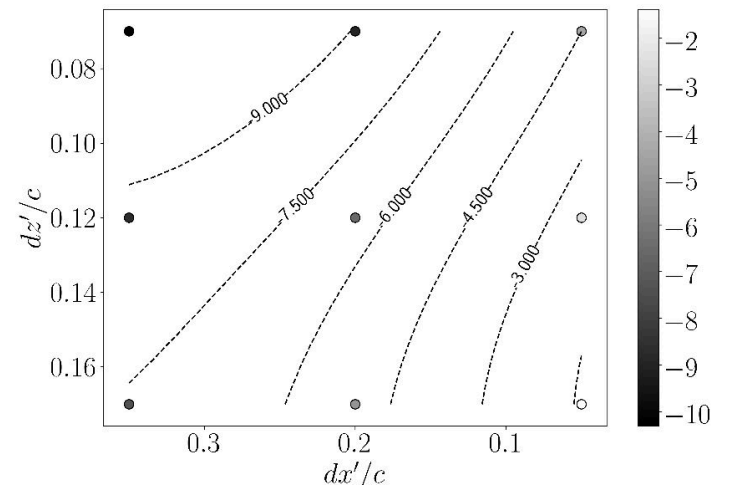

(a) E1 $\Delta C_{d}^{\text {Core }}(\%)$

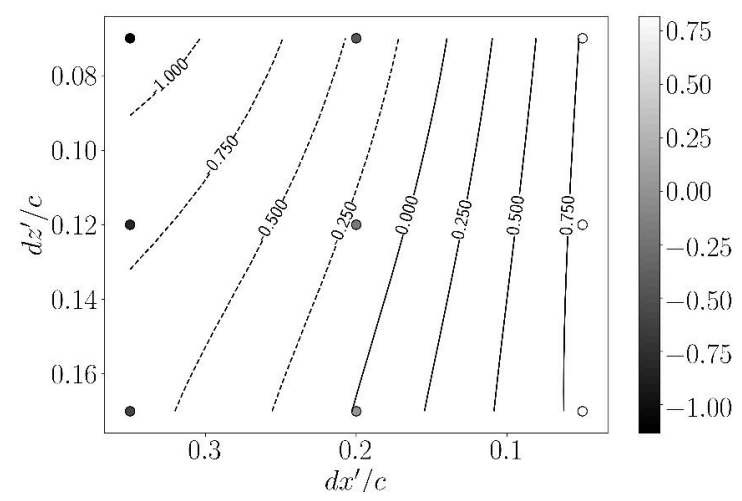

(b) E2 $\Delta C_{d}^{C o r e}(\%)$

Figure 8: Variation of installed core discharge coefficient relative to isolated engine at constant lift for a) E1 and b) E2. Dashed lines denote negative values. 

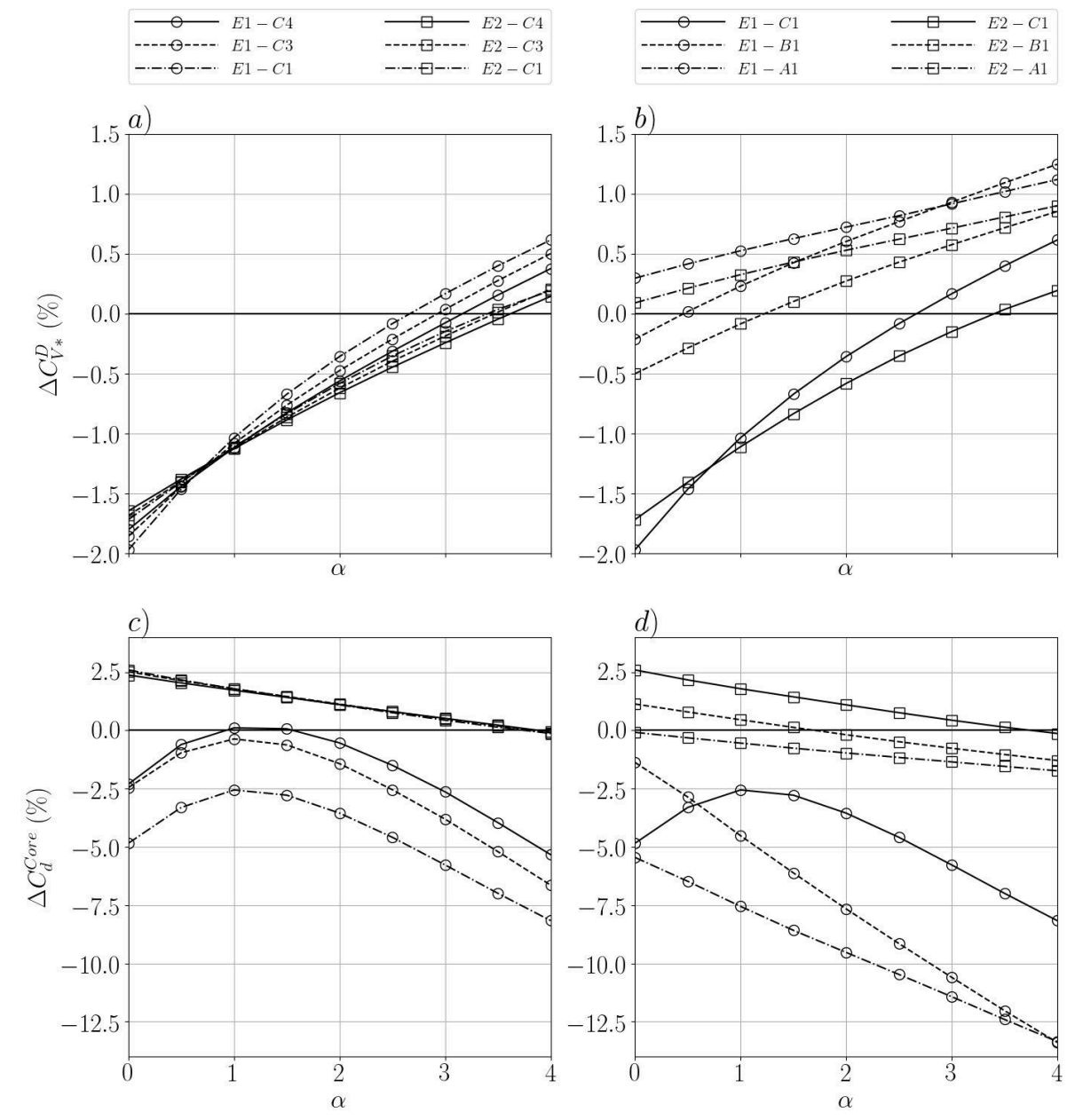

Figure 9: Variation of nozzle performance metrics with aircraft incidence and engine position relative to isolated engine for a) and b) Modified velocity coefficient c) and d) core discharge coefficient 


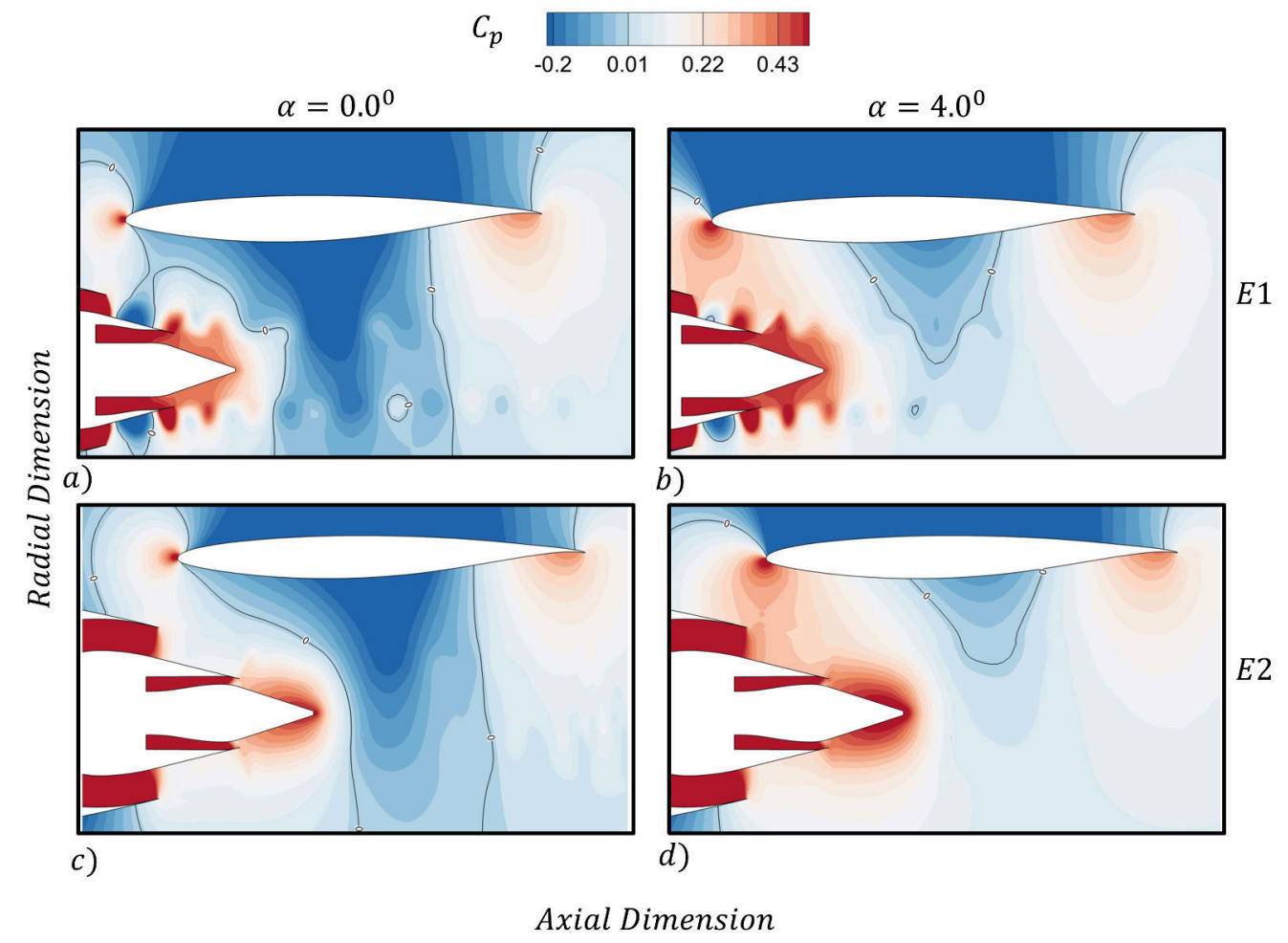

Figure 10: Variation of static pressure coefficient through the engine midsection for the E1 engine at a) $\alpha=0.0$ b) $\alpha=4.0$; the E2 engine at c) $\alpha=0.0$ and d) $\alpha=4.0$ in position $\mathrm{C} 3(d x / c=0.05, d z / c=0.17)$ 


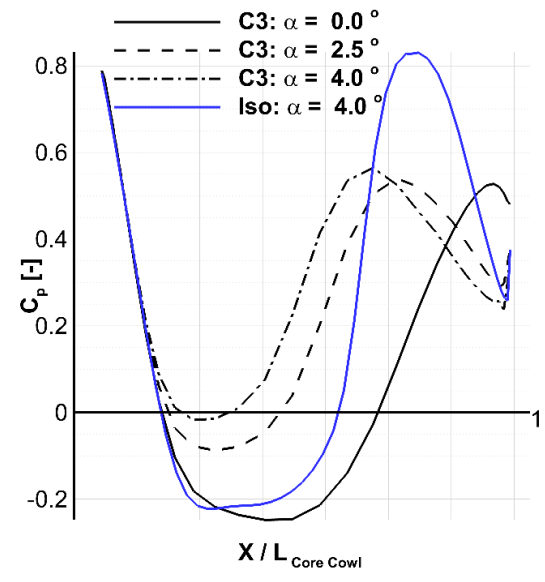

(a) Engine in position C3

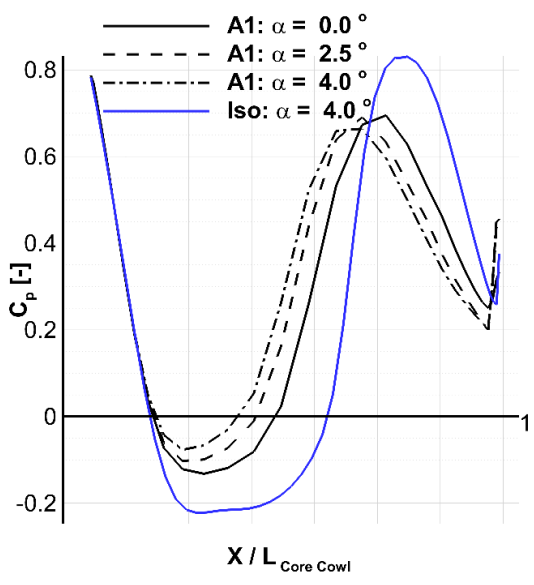

(b) Engine in Position A1

Figure 11: Variation of static pressure along the E1 core cowl topline with airframe incidence. 
2019-04-02

\section{Installation aerodynamics of civil aero-engine exhaust systems}

Otter, John J.

Elsevier

Otter JJ, Stankowski T, Robinson M, MacManus DG. (2019) Installation aerodynamics of civil aero-engine exhaust systems, Aerospace Science and Technology, Volume 89, June 2019, pp. 345-355 https://doi.org/10.1016/j.ast.2019.03.046

Downloaded from Cranfield Library Services E-Repository 